\title{
Towards a Rhetoric of Informal Scientific Writing: Plausible Argument and Complex Reasoning
}

\author{
Michael P.Jordan \\ Queen's University at Kingston
}

This paper discusses the systems of evidence and proof used in law, social science and science, leading to an introduction of general credibility and patterns of everyday reasoning in informal scientific writing. For this genre, ethnomethodological and text linguistic approaches are shown to provide methods of understanding that complement and extend traditional philosophical and rhetoric methods. A formal science paper is discussed which deals essentially with conclusions and the supporting scientific observations and calculations, with some mention of causes. In a brief journalistic discussion of that paper, however, a broader perspective is taken; causes take on greater importance as they point to the solution to the problem raised by the conclusions. To demonstrate the complex reasoning involved in such articles, the short article is analyzed in detail using text linguistic principles. The individual logical relations and the ways they interact to create complex reasoning are shown to be a necessary part of the understanding of this "summary plus" prose form of explanatory prose.

\section{Introduction}

\section{The Importance of 'Evidence'}

The question as to what constitutes sufficient evidence to demonstrate a point of view is at the heart of any academic pursuit. It started of course with the Greek philosophers, who developed methods of formal logic that determine whether or not something has been proved. The concepts used for such analyses are necessarily formulaic and are based on short made-up examples of language with no communicative context. As we will see here, the complexities of real technical 
writing in practical circumstances often take us beyond the area where such approaches are useful.

The study of evidence is crucial in all aspects of law, and a great deal of work has been carried out on the principles and practices of using different forms of evidence for legal purposes (e.g., Achinstein, 1983; Eggleston, 1983). Although we cannot apply many of the specific rules of evidence directly to the language of technical writing, the underlying principles do have relevance. The question as to what constitutes adequate evidence, and the recognition that the level of proof required depends on the importance of the matter are two such principles that find parallels in many genres of business and technical writing.

Lerner (1958) explores the connections of the use of evidence in law, history, nuclear research and social research, and Phelan (1996) does the same for the social sciences. Toulmin (1964) argues that the same principles of evidence apply to many branches of study, although Gaskin (1992) makes a strong case that the principles are different in legal use. Many of the underlying principles can be traced to traditional rhetorical techniques of argument and persuasion and to the well-known fallacies recognized by the ancient philosophers; see Neel, 1994 and Kennedy, 1994 for recent discussions. These principles have influenced the teaching of effective writing. Janis (1977: pp.135 to 169), for example, provides a useful summary of the usual classes of evidence, including fact, opinion, reasoning, analogy, consistency of belief, authority and emotive language.

\section{Everyday Reasoning}

However, the work by Toulmin (1964:pp.97 to 107) on the uses of argument, by Johnson-Laird (1986:pp.13 to 50) on "common-sense" reasoning, and by Walton (1992:pp.161 to 234) on plausible argument in everyday conversation all point to the need for analysis of reasoning in actual language use outside the restrictive confines of formal logic and the courts. Perkins (1985) claims that everyday and formal reasoning are different processes which have little in common, a view supported by Baron (1988:pp.178 to 194), who places everyday reasoning within a "search-inference" framework based on Toulmin's (1964) system of "Datum, Claim, Warrant and Backing". Collins and Michalski (1989) extend logic by proposing new types of syllogism to account for what they call "plausible reasons" - what Toulmin had earlier called "reasoning with qualifiers". Kuhn (1991) explains the use of counter-arguments (pp.104 to 144), rebuttals (pp.145 to 171) and the evaluation of evidence (pp.204 to 239) for everyday issues. More recently, Garnham and Oakhill's (1994:pp.255 to 273) chapter on "Everyday Reasoning" discusses the pioneering work of Perkins (1985), Galotti (1989) and Perkins, Faraday and Bushey 
(1991), demonstrating that the subject is now of serious academic interest.

Once we enter the realm of everyday reasoning, there appear to be few rules, although Johnson-Laird (1986) still creates one:

Reasoning without [formal] logic consists of three simple stages: interpret the premises by constructing a world based on their truth conditions, formulate an informative conclusion, and then check the conclusions by searching for different models of the premises (p.46).

This approach follows Toulmin's $(1964,1979)$ analysis of cognitive processes and his "evidence to claim" sequence and related complex variations. It is procedural rather than substantive, and is reflected in some textbooks on business (e.g., Saunders, 1992:pp.231 to 300) and technical (e.g., Lannon, 1994:pp.34 to 61) writing.

\section{Proof in Scientific Writing}

The question as to what constitutes adequate proof is fundamental to the philosophy of science, and this has led to an extensive body of knowledge concerning deduction, induction and reasoning dealing with scientific theories, evidence and proof; Giere $(1979,1984)$ and Aikenhead (1991) provide useful discussions. The contents and structures of formal scientific papers follow established procedures for task definition and refinement, methodology, observations, mathematical modelling, comparison with the data and results from other workers, analysis and conclusions. The related need for rigorous proofs of different types is also well established for mathematical derivations (e.g., Girard et al., 1989), which often form the central feature of scientific texts. However, the well-established principles of scientific enquiry and proof are, like those involved with other academic subjects, being re-examined. Again the concepts are more "fuzzy" and less applicable to formal structures of reasoning and logic than had previously been thought (Mamdani and Gaines, 1981).

The philosophical/procedural approach to evidence and proof is reflected in textbooks on science and technical writing. What little advice there is about evidence and proof relies heavily on the principles of traditional logic, rather than accepting the "fuzzier" concepts involved with "everyday reasoning", or the unarticulated "bridging" between premises and conclusion (Clark and Havilland, 1977; Parker and Riley, 1994), or the cumulative building of a credible case by several elements of parallel proof (Jordan, 1987). Also, in less-formal genres once we leave the strict "experimental/analysis" procedure, we find that there is a need to include the relations that deal with causes and their effects, purposes and the means of achieving 
them, and problems and their solutions - as well as the conclusions and the evidence, grounds or reasoning that supports it. While there may be some pedagogical validity in a strictly evidential-conclusion approach for explaining the structure of formal papers, we should recognize the need to understand, and teach, all the logical structures which are prevalent in the less-formal genres.

\section{The Ethnomethodological Approach}

\section{Rejection of the Philosophical Perspective}

The largely philosophical and procedural approach to the analysis of scientific discourse proved unsuitable for Woolgar's (1980) discussion of logic and sequence in scientific text. Using an ethnomethodological approach to investigate the social process of scientific investigation, he largely rejects the traditional philosophical approach:

A fruitful understanding of the nature of scientific enquiry must eschew many of the features of philosophical and sociological perspectives on knowledge production (p.239).

Also writing within the ethnomethodological tradition, Collins (1975) makes a persuasive case for detailed analysis of the scientist's actions in understanding the scientific process. Smith (1978) goes further by claiming an essential congruence between the concept being studied and the way the text that describes it is organized:

The method of analysis assumes that the structure of the conceptual scheme...is isomorphic with that organizing the text (p.23).

This is the view expressed by Woolgar (1980) as his central assumption: "that of isomorphism between presentational context and scientific concepts" (p.239).

\section{Extending the Congruence}

Woolgar view of isomorphism between scientific procedure and text organization does not go far enough as the scientific processes actually determine both the contents and the structures of texts that describe them, i.e., the texts reflect the thought/action patterns of the scientists as they go about their work of observation, analysis, assessment and discovery. This would explain why Woolgar fails to come to grips with the vital language issues of the text he analyzes - and why he excludes the vital thoughts and actions of those involved in the scientific process. He analyzes a part of Professor Anthony Hewish's December 12, 1974 Nobel Prize address entitled "Pulsars and High Density Physics", included below with key signalling devices highlighted in boldface. 


\section{Discovery of Pulsars}

The trail which ultimately led to the first pulsar began in 1948 when I joined Ryle's small research team and became interested in the general problem of the propagation of radiation through irregular transparent media. We are all familiar with the twinkling of visible stars and my task was to understand why radio stars also twinkled. I was fortunate to have been taught by Ratcliffe, who first showed me the power of Fourier techniques in dealing with such diffraction phenomena. By a modest extension of existing theory I was able to show that our radio stars twinkled because of plasma clouds in the ionosphere at heights around $300 \mathrm{~km}$, and I was also able to measure the speed of ionospheric winds in this region.

My fascination in using extra-terrestrial radio sources for studying the intervening plasma brought me to the solar corona. From observation of the angular scattering of radiation passing through the corona, using simple radio interferometers, I was eventually able to trace the solar atmosphere out to one half the radius of the Earth's orbit.

In my notebook for 1954 there is a comment that, if radio sources were of small enough angular size, they would illuminate the solar atmosphere with sufficient coherence to produce interference patterns at the Earth which would be detectable as a very rapid fluctuation of intensity. Unfortunately the information then available showed that the few sources known were more than one hundred times too large to produce this effect, and I did not pursue the idea. This was sad because the phenomenon was discovered by chance, about eight years later, by Margaret Clarke long after I had forgotten all about my comment. She was involved with a survey of radio sources at Cambridge and noticed that three particular sources showed variations in intensity. (from Woolgar, 1980:p.249)

Woolgar discusses the opening, externalizing devices, pathing devices, sequencing devices and (formal) logic of the presentation. However, he does not identify or discuss: the scientist's goals and methods of achieving them, what observations and calculations led to the discoveries and what theoretical and observational basis was used to establish them, the intellectual problems and their solutions, the related cause-effect relations or the scientist's assessments and their reasons. The view taken here is that, for informal genres such as this, a real understanding of the process and the text requires a detailed understanding and analysis of how the text reflects the goals, intentions, plans, actions and assessments of the scientist. 
To do this, we need to go beyond formal logic and plausible reasoning per se., as Woolgar has done. But we need to go further by taking note of all the logical relations of a text into account. These are usually indicated by specific signals in the discourse (as shown in boldface above). For the above extract, the following types of logical connection are indicated: led to indicates Effect, task indicates Purpose, why indicates Basis, by indicates Means, because indicates Effect, brought me to indicates Assessment, using indicates Means, if indicates conditional Cause, to indicates Purpose, unfortunately indicates Problem, too indicates Problem, effect indicates Effect, sad is a negative conclusion indicating Problem, because indicates Basis and noticed indicates Basis. That is, for this type of text, we cannot simply ignore Cause-Effect, Purpose-Means and ProblemSolution and concentrate solely on Assessment-Basis, even if that is taken to mean plausible rather than formal reasoning. The text, and the thoughts and actions it represents, is much more complex than that, and so a similarly complex explanatory model is needed to explain it. These relations have already been shown to be significant for openings in informal scientific texts (Jordan, 1991) and will now be applied to all aspects of the text.

\section{The Text Linguistic Approach}

\section{Macrostructure and Microstructures}

As text linguists have based their analyses on examples of actual language use (rather than the philosophical method of making up short acontextual examples), their conclusions are of special relevance to researchers and teachers of technical writing. In some work, the emphasis has been on overall patterns of discourse (e.g., Burke, 1968; Longacre, 1972; Winter, 1976; van Dijk, 1977) although Burke and Longacre in particular were also interested in the micro-patterns of structure within the larger "macrostructure" (van Dijk, 1977). These patterns have been derived mainly for dramatic (Burke) and narrative structures although Winter, Hoey (1983), Jordan (1984) and van Dijk concentrated on the four-part structure of "Situation-Problem-Solution-Evaluation" for engineering and scientific texts.

Other linguists (e.g., Beekman and Callow, 1974; Hutchins, 1977; Winter 1982) have examined the "relational propositions" or "clause relations" that exist between almost any two stretches of text - and from section, span and paragraph level down to (and even within) sentences, clauses and noun phrases (Jordan, 1998a). The "rhetorical structure theory" developed by Mann and Thompson $(1986,1989)$ is based on a central rhetorical statement from which the various semantic relations can be seen to develop in complex, though essentially binary, patterns. They include 
the established individual relations of Basis-Assessment (called "evidence" and "justify") and Cause-Effect in their analysis and also develop relations dealing with "solutionhood" and "enablement". As all these patterns of meaning apply at the overall "macrostructure" of the texts as well as at much lower levels, they occur in complex groupings in achieving effective patterns that demonstrate points of view.

\section{The "Logical" Relations}

Although philosophers define logic in terms of formal reasoning and inference, some linguists use a broader definition, as in Ballmer's "Logical Grammar" (1978) and Labov's "The Logic of Non-Standard English" (1970). Less broadly, Halliday's general use of the "logic of language" (1978:p.86) and Martin's "logico semantic relations" (1992:pp.178 to 179) include addition, comparison and temporal as well as consequential relations. Winter's (1982) “logical sequence" relations concentrate much more on the meanings involved with deduction, effect and instrument, and it is this set of meanings that I include in my use of the term (Jordan, 1997). More specifically, I am concerned with the binary pairs of relations that deal with: (a) Assessment-Basis (an assessment, judgment or opinion together with the evidence, basis or grounds that justify it), (b) Cause-Effect (an event and the circumstance that makes it happen) and (c) Purpose-Means (a goal, aim or ambition together with the means, plans or methods used to achieve it). The Problem-Solution pair is very close to Purpose-Means; Solution and Means are the same, and the Purpose is a decision to seek to overcome the Problem. The relation of Enabler-Enablement (Lowe, 1987:p.37; Mann and Thompson, 1989:p.15), which has three sub-relations of Possibility, Permission and Requirement (Jordan, 1998b:pp.294 to 295), is semantically close to that of Purpose-Means.

The distinction between Assessment-Basis and Cause-Effect has led to confusion in the work of a number of linguists. The former deals with considered judgment (and actions depending on such judgments) and the reasoning for it, whereas Cause-Effect is "the unwitting (generally inanimate) cause of an event" (Quirk et al., 1972:p.351), where there is no conscious choice in real life. This is in line with Anscombe's (1957) distinction that it is a "cause" if there is a mere response to something, but a "reason" if thought or consideration are involved. Mann and Thompson's "non-volitional result" (1989:p.62) is a Cause-Effect relation dealing with "stimulus-response" reactional human behaviour although of course Assessment-Basis is involved if the response (even anger, pleasure, etc.) is a considered reaction. Some of the signalling of the Cause-Effect and AssessmentBasis relations is unreliable in English; for example, as a result and caused can be used to indicate Assessment-Basis, and consequently can indicate Cause-Effect 
(Jordan, 1997:pp.327 to 330). Some such relations are not signalled at all (Crothers, 1979).

The analysis presented in the next section of this paper shows how these relations combine in complex ways to create an informative journalistic scientific text. It provides an example of how they are used by a skilled writer to explain the work, plans, thoughts and conclusions of those involved with the project described.

\section{Text Analysis}

\section{The Article Analyzed}

The article analyzed here, entitled "The Long Goodbye", is from the March 20, 1999 (p.4) issue of New Scientist, and is reproduced here with the kind permission of the editors of that publication. New Scientist is recognized for its clear explanations of scientific discoveries and developments for general science readers. The shorter articles, like the one analyzed here, usually provide summary information from scientific work published elsewhere, often with some surrounding background to, and relevance of, that work. They thus serve the useful journalistic purpose of making detailed scientific work more accessible and relevant to their readers.

The article is based on a scientific paper (Caswell et al., 1999), which has an essentially Assessment-Basis structure, dealing with predictions about the numbers of "right" whales and their decreasing populations. These conclusions are all well justified in the original article by full details of the method used, the observations made and mathematical calculations based on assumptions regarding expected death and birth rates. Given the many factors that could affect the continuing survival of the species, the conclusions reached by Caswell et al. cannot be established in anything like a formal way in terms of classical deduction. However, they make a convincing case for the critical scientific community, based on observed data, mathematical modelling and references to other published work on related topics. They also mention collisions with ships and damage by fishing nets as contributory causes of the diminishing numbers.

"The Long Goodbye" is close to what Russell (1992) terms "popularized summaries", which "condense and adapt specialized material for general readership" (Russell, 1994:p.38). However, it fits into the category of a summary that goes beyond the extent of the original document, as opposed to those that restrict themselves to the information in the source text (Laurent, 1985:p.84). It may even be inappropriate to refer to it as a "summary", as it includes significant information that is not in the original article. Like the original article, "The Long Goodbye" identifies the numbers of right whales and the problem of its possible extinction; it 
also deals with collisions with ships as a major cause of the problem. Unlike the original article, however, “The Long Goodbye" goes beyond the central gist of the original article by discussing the planned legislated Solution, how it works, and Caswell's optimistic assessment of that attempted Solution. It also adds new information in support of the conclusions reached by the researchers.

The broader account offered in this article essentially has a Problem-Solution structure (the decline as the Problem, and legislation as the suggested Solution) as it places the scientific work of the original paper within this broader framework. The important Assessment-Basis pair dealing with the researchers' conclusions and the justification becomes a microstructure within the Problem Identification element of the macrostructure. Both the original paper and the article presented here also involve the Causes of the decline, i.e., within the macrostructure are also CauseEffect microstructures. And within these relations, we also find lower level microstructures of Purpose-Means and other logical connections, which intermingle to create the complex reasoning for the article analyzed here. The next section provides a detailed analysis of the logical relations in the article "The Long Goodbye".

\section{The Article}

The article is reproduced below, with boldface added to highlight signals of the logical relations; numbers have been added to the paragraph to help you to follow the analysis that follows. The caption for a photograph of a mature and baby whale is: Slip sliding away: slow reproduction and collisions with ships mean the right whale is in decline

\section{The long goodbye}

Saving a whale from hunting doesn't always keep extinction at bay

1. The North Atlantic right whale is slowly disappearing. On current trends, it will be extinct in less than 200 years, say biologists in Massachusetts. The main problem is the number of whales being hit by ships.

2. The northern right whale - so named because it was the "right" whale to hunt - was nearly wiped out by commercial hunters. After whaling ended in 1935 , its numbers began to recover, but only slowly. Roughly 300 right whales now live in the North Atlantic, mostly only along the North American seaboard. With so few animals, marine biologists have found it hard to discover whether the population is still increasing.

3. To answer the question, researchers led by Hal Caswell, a mathematical ecologist at the Woods Hole Oceanographic Institute on Cape Cod, compiled 
data from photographic records of right whale sightings since 1980. The researchers could easily tell the whales apart, because each bears a distinct pattern of scars and calluses. From these records, Caswell calculated the average survival rate. "There was a very strong declining trend in survival probability," he says.

4. In order to determine the overall rate of population growth, the researchers factored in data on the whales' reproductive rates. In 1980, they estimate, the population was growing at 5.3 per cent a year. By 1994, however, it was declining by 2.4 per cent a year, Caswell and his colleagues report this week in the Proceedings of the National Academy of Science (vol. 96, p. 3308).

5. Modelling the dynamics of whale populations is notoriously difficult. But other biologists feel Caswell's analysis is sound. Unfortunately, what he has predicted may come true," says Amy Knowlton, an expert on right whales at the New England Aquarium in Boston.

6. Experts blame a rise in shipping for the right whale's decline. Of 43 deaths documented since 1970, 15 were caused by collisions with ships. The problem is that right whales swim quite slowly in areas where there is a lot of shipping. Birth rates have also declined, possibly due to inbreeding or coastal pollution.

7. Caswell hopes that new legislation in the us will halt the decline. From July, ships entering critical right whale habitats off New England and the coast of Florida will be required to contact the us Coast Guard for the latest whale sightings. "The trend in survival rates could be reversed very quickly if the policy works," says Caswell.

Jonathan Knight

Analysis

With slip sliding away alluding to the decline in numbers, the photograph caption identifies two Problems (the slow reproduction rate, and the collisions with ships), which are both Causes of the main Problem: the whales being in decline. The main title alludes to the predicted extended death of the species, and the sub-title indicates that one already-implemented Attempted Solution (Saving the whale from hunting) is not a complete Solution to the threat (a Problem) of extinction for the species.

The first paragraph identifies the problem (disappearing) and its extent (extinct in less than $\mathbf{2 0 0}$ years), together with the source of that conclusion. The 
main problem, noted in the caption as a Cause of the decline, is the number of whales being hit by ships.

In Paragraph 2, Background information about the name of the right whale is followed by the earlier Problem (nearly wiped out) and its Cause (by commercial hunters) in the grammatical form of agent. After signals the CauseEffect relation (as well as time) that the cessation of hunting (a Solution) led to the slow recovery. Similarly With (= Because of) indicates that there being only few animals is a Cause of the Problem (hard) for the ecologists in seeking to satisfy their intellectual "need-to-know" Problem regarding the growth or decline in population. (See Jordan, 1997:pp.332 to 333 and 336 to 337 for these and other subtle signals of logical connection.)

In Paragraph 3, The task To answer that question is a Purpose, and the Means of seeking to achieve it is given in the remainder of that sentence. The data will form part of the Basis for their Assessment to come. The speciality of Caswell and his colleagues and their affiliation with the well-known Woods Hole Oceanographic Institute both provide a form of credibility for the individuals and thus also the conclusions they have reached. The central sentence explains (in Assessment-Basis terms signalled by because) what Solution the ecologists used to overcome a Problem they had in using the photographs as reliable evidence for their conclusions. The last two sentences provide details of the analysis and conclusion reached Based on the photographic evidence. The conclusion of very strong declining trend in survival probability is a Problem for the ecologists, for which a Solution will be sought.

A second Purpose (In order to) is identified in the initial clause of Paragraph 4 , and this is followed by the Means of achieving it in the same sentence. The mediating however separates details of the positive results (growing) for 1980 and the negative results (declining) for 1994. Publication details follow.

In Paragraph 5, the Problem with the reliability of such estimates (notoriously difficult) is conceded, followed by the concurring Assessment (sound) from other biologists as a rebuttal and with but signalling the transition. The Assessment from one such biologist is given as supporting credibility for Caswell et al.'s Assessment; it is signalled as Problem by Unfortunately. Labelling Amy Knowlton as an expert and indicating her position at the reputable New England Aquarium in Boston both provide support for the person and thus the conclusion she has reached.

In Paragraph 6, the first statement is a negative (blame) Assessment indicating what they view as the Cause (a rise in shipping) of the Problem (the right whale's decline), which is the Effect. The next sentence provides some factual evidence as Basis for their Assessment of Cause; this is in terms of an Effect-Cause pair signalled 
by caused, and the Cause (collisions with ships) is clearly a Problem. The second sentence indicates a related Problem (problem), which is a contributory Cause of the earlier Problem of the collisions. The decline in birth rates noted in the last sentence is another Cause of the right whale's decline (not the collisions), and two further possible (possibly) Causes for this are noted at the end signalled by due to. The information in the last sentence is in the form of Assessments, for which no Basis is given here.

The final Paragraph introduces a Solution (new legislation in the us) together with Caswell's Assessment expressing his hope that it will halt (a positive Assessment) the decline (the Problem); the legislation and the halting form an anticipated Cause-Effect relation. The legislation will require (be required) ship captains to obtain details of the whales' whereabouts, and presumably avoid them; this is an Enabler-Enablement relation of Requirement. No Basis is given here for Caswell's final Assessment, which is a conditional (if, could) Effect-Cause relation.

\section{Assessment and Implications}

\section{Credibility, Purpose and Complexity}

Within the macrostructure dealing with the extinction Problem and the legislated attempted Solution, the author presents a credible enough case for the claim that factors other than hunting can lead to the extinction of the right whale - and also for the rate of decline, their causes and the possible effectiveness of the planned solution. The cases that are presented for these several different conclusions, however, are not ones that philosophers would recognize as being "logical", and rhetoricians would be hard pressed to explain them fully in terms of classical rhetorical principles of evidence and argument. They may not meet the "beyond a reasonable doubt" criterion in criminal law although the civil level of "the preponderance of evidence" probably is achieved. They are certainly adequate for the purpose of this article.

For the central claim of a recent annual decline of 2.4 per cent, the article presents both substantive and other types of support. Substantively, the case presented depends on data derived from photographic evidence, calculations based on these recorded observations, and the use of additional factors for birth rate; the possible unreliability of the photographic evidence is addressed, and the notorious difficulty of obtaining reliable data is conceded and rebutted by the views of other experts. Credibility for Caswell et al.'s claim is also enhanced by the workers' speciality and affiliation, by the concurrence of other biologists, by the opinion specifically of one other expert, and by her identified expertise and affiliation. 
The purpose of general journalistic articles such as this one is to provide readers with information about recent scientific work and discoveries, and to provide additional comment and information so that readers can understand the credibility, relevance and importance of those scientific advances. The writer goes beyond a summary of the results and comments of the original work by also including the problems encountered and workers' aims, methods, thoughts, hopes and plans. He also discusses the views of other experts on the subject to support those of the main worker and his colleagues. In presenting these types of information, the writer uses several types of binary logical pairs: not just Assessment-Basis, but also PurposeMeans, Problem-Solution, Cause-Effect and Enabler-Enablement. These pairs occur in either order, in complex combinations and at different grammatical and structural levels to create a complex set of microstructures. To indicate these different relations, the writer uses a variety of signalling devices and transitions between the paragraphs, sentences and clauses.

\section{Everyday Reasoning}

Both classical deductive reasoning and the looser forms of "everyday" reasoning are embraced within the broad Assessment-Basis (or "Statement-Justify" or "Claim-Warrant") pair traditionally used in text linguistic analyses. While conclusions that rely inexorably on the premises made and the evidence presented are undoubtedly ideal for formal situations, real-life conclusions and decisions are rarely that clear cut. So instead writers rely on whatever forms of evidence and plausible arguments they can muster in support of their contentions. In all walks of life (perhaps especially in law), parallel elements of support often "add up to" the conclusion reached, and these in turn often have their own form of credibility to create credibility "trees" (Jordan, 1987).

For informal scientific texts such as the one analyzed here, there are no formal "rules" for judging the evidence provided. The question as to whether something has been "proved" in a formal sense does not arise as there are no recognizable scales of "value" for the different forms of evidence presented. In practice, what is adequate evidence is often more a matter of the importance of the subject than the substantive nature of the justification offered. In terms of Grice's (1975) notion of quantity - that we only present sufficient information and no more - we have to recognize that additional evidence beyond that which is reasonable and adequate for the circumstances would be inappropriate. For the article analyzed, enough justification is presented and further supporting evidence would have been out of place.

As we have seen here, the concept of credibility and reasoning in informal 
scientific genres cannot be viewed in isolation from the other "logical" relations dealing with Causes, Problem and Purposes. As a negative Assessment is a Problem and as Problems do not just happen but are Caused, it is hard to avoid these other concepts when dealing with real-life situations. Similarly as Assessments and judgments are made by individuals and not things or machines, Purposes and Enablements are also involved together with the Means of achieving them. Thus only a multi-relational approach to the critical review of informal science literature is likely to suffice.

\section{Towards a Critical Analysis of Science Writing}

As the pedagogical value of literary criticism has long been established and many teachers of technical writing have related skills, experience and interests, it would seem appropriate to establish parallel approaches for the critical assessment of scientific, technical and business communications. With sensitivity towards the many genres in use and the effects these have on purpose, content and structure, we might well develop the text linguistic approach adopted here to help in the analysis and appreciation. We could not, of course, simply adapt principles of literary criticism to the analysis of scientific and engineering writing. The former is more concerned with specific writers, protagonists and created occurrences, whereas the latter is concerned more with factual observations, mathematical modelling, connection with similar established results and establishing a credible case for new understandings of real phenomena. But by using the approach discussed here, we could develop a parallel form of critical assessment that is at least as meaningful and intellectually defensible as the analysis used for literary works (see Bazerman, 1988).

A further advantage of detailed textual analysis for teachers of technical writing is that it provides a sound, and very interesting, vehicle for teaching almost any aspect of language use. For the article analyzed, for example, we can learn much about genre, purpose, audience, summaries, paragraphing, structures, logical relations - and the use of titles, sub-titles, captions and photographs. In the language itself, we also see interesting examples of time subordination (After, In, By, From July), logical subordination (On, With, because (2), due to, From, if, To, In order to), transitions (but (2), however), restrictive (being, led, where) and non-restrictive (named, a, an) clauses, signals of doubt (could (2), possibly, estimate), what (what) and -ing (Modelling) nominals, existential there and anticipatory it. For teachers of technical writing who are brave enough to explore actual language use in detail with their students, such articles are a gold mine for discussion, instruction and learning. 


\section{References}

Achinstein, Peter (1983). The Concept of Evidence, Oxford: Oxford University Press.

Aikenhead, Glen S. (1991). Logical Reasoning in Science and Technology, Rexdale, ON: John Wiley.

Anscombe, Gertrude E.M. (1957). Intention, Proceedings of the Aristotelian Society, 57, 321-332.

Ballmer, T.T. (1978). Logical Grammar, Amsterdam: North Holland.

Baron, Jonathan $(1988,1994)$. Thinking and Deciding, Cambridge: Cambridge University Press.

Bazerman, Charles (1988). Shaping Written Knowledge: The Genre and Activity of the Experimental Article in Science, Madison, WS: University of Wisconsin Press.

Beekman, John and John Callow (1974). Translating the Word of God, Grand Rapids, MI: Zondervan.

Burke, Kenneth (1968). Dramatism. In: D.Sills (ed.), The Intermational Encyclopedia of the Social Sciences, Vol. 7, New York, NY: Macmillan.

Caswell, Hal, Masami Fujiwara, and Salange Brault (1999). Declining Survival Probability Threatens the North Atlantic Right Whale, Proceedings of the National Academy of Sciences of the United States, 96(6), 3308-3318.

Clark, Herbert H. and S.Havilland (1977) Comprehension and the GivenNew Contract. In: Roy O.Freedle (ed.), Discourse Production and Comprehension, Norwood, NJ: Ablex, 1-40.

Collins, Allan and Ryszard Michalski (1989). The Logic of Plausible Reasoning: A Core Theory, Cognitive Science, 13(1), 1-49.

Collins, Harry M. (1975). The Seven Sexes: A Study of the Sociology of a Phenomenon, or The Replication of Experiments in Physics, Sociology, 9, 205-224.

Crothers, Edward (1979). Paragraph Structure Inference, Norwood, NJ: Ablex. 
Eggleston, Richard (1983). Evidence, Proof and Probability, London: Weidenfeld and Nicolson.

Galotti, Kathleen M. (1989). Approaches to Studying Formal and Everyday Reasoning, Psychological Bulletin, 105, 331-351.

Garnham, Alan and Jane Oakhill (1994). Thinking and Reasoning, Oxford: Blackwell.

Gaskin, Richard H. (1992). Burdens of Proof in Modern Discourse, New Haven CT: Yale University Press.

Giere, Ronald H. (1979, 1984). Understanding Scientific Reasoning, New York, NY: Holt Rinehart and Winston.

Girard, Jean-Yves, Yves Lafont and Paul Taylor (1989). Proof and Types, Cambridge, Cambridge University Press.

Grice, H.Paul (1975). Logic and Conversation. In: Peter Cole (ed.), 41-58, Syntax and Semantics, Vol. 3, Speech Acts, New York, NY: Academic Press.

Grimes, Joe (1993). The Thread of Discourse, The Hague: Mouton.

Halliday, Michael A.K. (1978), Language as a Social Semiotic, Bath, England: Edward Arnold.

Hoey, Michael P. (1983). On the Surface of Discourse. London: Allen and Unwin.

Hutchins, W.John (1977a). On the Surface of Scientific Discourse, UEA Papers in Linguistics 5 (3), Norwich, Norfolk: University of East Anglia, 18-39.

Hutchins, W.John (1977b). On the Problem of "Aboutness" in Document Analysis, Journal of Informatics, 1(1), 17-33.

Janis, Jack H. (1977). College Writing: A Rhetoric and Handbook, New York, NY: Macmillan.

Johnson-Laird, Philip N. (1986). Reasoning Without Logic. In: Terry Myers,

Keith Brown and Brendan McGonigle (eds.), 13-50, Reasoning and

Discourse Processes, London: Academic Press.

Jordan, Michael P. (1984). Rhetoric of Everyday English Texts, London: Allen and Unwin.

Jordan, Michael P. (1987). The Language of Evaluation, Technostyle, 6(2), 1-10. 
Jordan, Michael P. (1991). Openings in Informal Scientific Texts, Technostyle, $9(2), 1-20$.

Jordan, Michael P. (1997). Subtle Signalling of Logical Relations in News Reporting. In: Alan KMelby (ed.), 325-340, The 23rd LACUS Forum, Chapel Hill, NC: Linguistic Association of Canada and the United States.

Jordan, Michael P. (1998a). Pragmatic, Stylistic and Grammatical Limitations on Choice: A Study of Cause-Effect Relations in English. In: Antonia SBnchez-Macarro and Ronald Carter (eds.), 65-86, Linguistic Choice Across Genres: Variation in Spoken and Written English, Amsterdam: John Benjamins.

Jordan, Michael P. (1998b). Enabler-Enablement Relations in English. In: Sheila Embleton (ed.), 290-303, The 24th LACUS Forum, Chapel Hill, NC: Linguistics Association of Canada and the United States.

Kennedy, George A. (1994). A New History of Classical Rhetoric, Princeton: Princeton University Press.

Kuhn, Deanna (1991). The Skills of Argument, Cambridge: Cambridge University Press.

Lannon, John M. (1994). Technical Writing, New York, NY: Harper Collins.

Labov, William (1970). The Logic of Nonstandard English, Georgetown University Monograph Series of languages and Linguistics, 22.

Laurent, J.P. (1985). L'apprentissage de l'acte de résumer, Pratiques. 48, 71-89.

Lerner, Daniel and Raymond Aron (eds.) (1958). Evidence and Inference, Glencoe, IL: The Free Press.

Longacre, Robert E. (1972). Hierarchy and Universality of Discourse Constituents in New Guinea Languages, Georgetown: Georgetown University Press.

Longacre, Robert E. (1983). The Grammar of Discourse, Notional and Surface Structures, New York, NY: Plenum Press.

Lowe, Ivan (1987). Two Ways of Looking at Causes and Reasons. In: Jim Monaghan (ed.), 37-46, London: Frances Pinter.

Mamdani, E.H. and Brian R.Gaines (eds.) (1981). Fuzzy Reasoning and its Applications, London: Academic Press. 
Mann, William C. and Sandra A.Thompson (1986). Relational Propositions in Discourse, Discourse Processes, 9(1) 57-90.

Mann, William C. and Sandra A.Thompson (1989). Rhetorical Structure Theory: A Theory of Text Organization. In: Livia Polanyi (ed.), The Structure of Discourse, Norwood, NJ: Ablex.

Martin, Jim (1992). English Text, Amsterdam: John Benjamins.

Neel, Jasper P. (1994). Aristotle's Voice: Rhetoric, Theory and Writing in America, Carbondale, IL: Southern Illinois University Press.

Parker, F. and K.Riley (1994). Linguistics for Non-Linguists, Boston, MA: Allyn and Bacon.

Perkins, Daniel N. (1985). Reasoning as Imagination, Interchange, 16, 14-26.

Perkins, Daniel N., M.Farady and B.Bushy (1991). Everyday Reasoning and the Roots of Intelligence. In: James F.Voss, Daniel N.Perkins and Judith W.Segal (eds.), 83-105, Informal Reasoning and Education, Hillsdale, NJ: Lawrence Erlbaum.

Phelan, Peter and Peter Reynolds (1996). Argument and Evidence: Critical Analysis for the Social Sciences, New York, NY: Routledge.

Quirk, Randolph, Sidney Greenbaum, Geoffrey Leech and Jan Svartvik (1972, 1985). A Grammar of Contemporary English. London: Longman.

Russell, Pamela (1992). The Integration of Theory and Practice in the Development of Summary-Writing Practices, PhD Dissertation, Université de Montréal.

Russell, Pamela (1994). Investigating Summary Typology: Considerations for Classification, Technostyle, 11 (3\&4), 37-47.

Saunders, Peter (1992). Strategy: Writing at Work, Toronto, ON: Harcourt Brace Jovanovich.

Smith, Dorothy E, (1978). K is Mentally Ill, Sociology, 12, 23-53.

Toulmin, Stephen E. (1964). Uses of Argument, Cambridge: Cambridge University Press.

Toulmin, Stephen E. (1979). An Introduction to Reasoning, New York, NY: Macmillan. 
van Dijk, Teun A. (1977). Text and Context: Explorations in the Semantics and Pragmatics of Discourse, London: Longman.

Walton, Douglas N. (1992). Plausible Argument in Everyday Conversation, Albany, NY: State University of New York Press.

Winter, Eugene, O.O. (1976). Fundamentals of Information Structure, The Hatfield Polytechnic (now Hertfordshire University).

Winter, Eugene.O.O. (1982). Towards a Contextual Grammar of English, London: Allen and Unwin.

Woolgar, Steve (1980). Discovery: Logic and Sequence in Scientific Text. In: Karin D.Knorr, Roger Krohn and Richard Whitley (eds.), 239-268, The Social Processes of Scientific Investigation, Dordrecht, Holland: D. Reidel. 